\title{
POESÍA DESNUDA Y SUCESIVA (NUEVAS NOTAS SOBRE LA INFLUENCIA DE MIGUEL DE UNAMUNO EN JUAN RAMON JIMÉNEZ)
}

\author{
Adolfo SOTELO VÁZQUEZ \\ Universidad de Barcelona
}

"Si sigues tu voluntad un día podrás reinarte solo enmedio de tu mundo" (Canciones de la nueva luz)

En un prólogo --uno más de su fascinante escritura sucesiva- fechado en 1953, Juan Ramón Jiménez escribía: "Un poeta ha de aumentar el mundo en alguna forma y manera por su pensamiento, su sentimiento o su expresión; por eso dije andaluz universal, cansado de su nombre, vencedor oculto y creador sin escape" . El poeta en su continuo nombrar descifra el mundo y, recíprocamente, se incorpora por lo creado al mundo. Tal proceso - la poesía juanramoniana es poetización sucesiva que radica en el anhelo de encontrar para el pensamiento, el sentimiento o la expresión su propia palabra, culmina en la forja de la poesía desnuda que es la forja de una individualidad creadora, la cual al romper los límites de lo coyuntural, lo castizo o lo acccesorio, - al beber en la fuente neoplatónica recordada por el gran Rubén de Prosas profanas ${ }^{2}$ - deviene en poesía universal y eterna.

1. JRJ, "Prólogo". Crítica paralela (ed. A. del Villar). Madrid, Narcea, 1975; p. 145,

2. Me refiero al poema "Joven, te ofrezco el don de esta copa de plata... Llena la copa y bebe: la fuente está en ti mismo" (Rubén Darío, Prosas profanas y otros poemas. París, Vda. de C. Bouret, 1901). Esta edición incluye el opúsculo de José Enrique Rodó, "Rubén Darío", sin firma. Posteriormente fue reimpreso en la edición de Prosas de 1908, ya con el nombre del gran crítico hispanoamericano. Ignacio M. Zulueta presenta una excelente información en su edición de Prosas profanas yotros poemas (Madrid, Castalia, 1983). M.H. Abrams escribe: "La familiar figura neoplatónica del alma como fuente o raudal que desborda es asimismo frecuente en la poesía romántica" (El espejo y la lámpara. Teoría romántica y tradición crítica, Barcelona, Barral, 1975; p. 112). 
Ahora bien, esta progresiva ruptura - puntualmente poetizada en los libros de Moguer, los amarillos y los inéditos- o este encuentro con la desnudez poética no es un cielo definitivo o un mar paralizado. La individualidad creadora se constituye a través del trabajo gustoso al mismo tiempo que la poesía se va haciendo progresivamente desnuda y esencial. Dicho de otro modo: el quehacer poético juanramoniano no es un mar de oleaje detenido, sino que su individualidad se va perfilando a medida que logra nuevas formas de indagación en su alma, receptáculo de la realidad toda. $\mathrm{Su}$ individualidad se conforma en su obra sucesiva. Idea capital en la estética del gran poeta andaluz que tiene su adecuación práctica en el continuo depurar — "Depurar, recrear, depurar, no tiene vuelta de hoja"3 — y en la obra como sucesión, que se concreta en un concepto del poetizar entendido como "venir a ser yo cada día en una nueva visión y una nueva expresión de mi mismo y del mundo que yo veo, mi mundo", haciendo de la transición permanente el estado más perfecto del artista.

Este sumario perfil de una de las ideas motrices de la estética juanramoniana - cuyo desarrollo desborda el objetivo del presente trabajo- deja entrever la deuda que el autor de Eternidades contrajo con una serie de reflexiones unamunianas que la edición de los Ensayos por parte de la Residencia de Estudiantes - con participación decisiva de Juan Ramón- vino a actualizar. Si en otro lugar ${ }^{5}$ he documentado la indiscutible presencia de Unamuno en la forja de la poesía desnuda, quiero apostillar con algunas nuevas notas lo incitante que resultó para el poeta de Moguer la lectura de Miguel de Unamuno en el momento de la identificación de su poesía con el nombre exacto de las cosas, función primera de la desnudez anhelada y conseguida, tras superar los vaivenes de su primera gran etapa poética.

Sin menoscabar un ápice la originalidad y maestría del poeta de Moguer, no se debe ignorar que el manantial que nutre su concepción de la

3. JRJ, Estética y ética estética (ed. F. Garfias). Madrid, Aguilar, 1962; p. 377.

4. JRJ, "La razón heroica" (1948). El trabajo gustoso (ed. F. Garfias), México, Aguilar, 1961; p. 126. Certeramente ha glosado esta idea juanramoniana el profesor F.J. Blasco: "Es la poesía, de un lado, una actividad espiritual, que puede definirse como reiterada expresión y toma de conciencia, por parte del poeta de su propio yo y del mundo. De otro, dicha actividad redunda en ese llegar-a-ser-yo; es decir, la actividad poética se traduce y se manifiesta, en el pensamiento de Juan Ramón, como diaria realización de un yo" (Poéticade Juan Ramón. Salamanca, Universidad de Salamanca, 1981; p. 210). En la magnífica Antología poética que Javier Blasco ha preparado recientemente invoca el origen hegeliano de esta idea de Juan Ramón (J. Blasco, "Introducción" a JRJ, Antología poética, Madrid, Cátedra, 1987; p. 38, nota 88). Creo, no obstante, que la raíz de tal planteamiento está más cerca del pensamiento krausista que del hegeliano, y así el propio Blasco lo deja entrever en sus penetrantes notas 133, 134 y 140 de la citada edición. No en balde Krause dejó escrito que "es el arte una manifestación constante, una función perpetua de la vida misma, con la cual crece y decrece, progresa y decae; función permanente como ella" (Krause, Compendio de estética traducción y notas de Francisco Giner, Madrid, V. Suárez, 1883 2; p. 89).

5. Adolfo Sotelo, "Miguel de Unamuno y la forja de la poesía desnuda de Juan Ramón Jiménez". Hispanic Review, 55 (1987); p. 195-212. 
poesía, e incluso las sugerencias unamunianas, viene de más lejos. En la forja de la poesía desnuda desembocan lecturas románticas: de Shelley, cuya Defensa de la poesía se traduce por primera vez al castellano en $1904^{6}$, de Coleridge, a quien tempranamente traduce Unamuno, de Blake —afín a ambos creadores 7 - y, como receptáculo general, del idealismo estético en sus vertientes hegeliana ${ }^{8}$ y krausista. Esta última corriente es capital en la configuración de la poesía desnuda, pues la presencia del ideario krausista en las formulaciones poéticas juanramonianas es patente desde los tiempos de Helios ${ }^{9}$. Así la órbita común del modernismo, en la que gira la poesía del joven Juan Ramón, se ve enriquecida por estímulos diversos en los que juegan papel de primer orden las consideraciones teóricas de Unamuno, ya sea en su vertiente metapoemática o ya en la torrentera de ideas que atesoran sus ensayos y artículos, reiteradamente elogiados por el autor de Platero y yo.

Juan Ramón en su camino hacia la desnudez poética creía que un plan definitivo ahorcaría el alumbrar sucesivo de palabras y con ello el "venir a ser yo cada día en una nueva visión". Se convertiría en una rutina como la modernista. Entender la poesía desnuda como un continuo y progresivo conocimiento del yo, como una continuada revelación de la propia individualidad creadora es punto clave de la nueva poética juanramoniana, consolidada en la poesía desnuda.

En Eternidades escribe:

6. P.B.Shelley, Defensa de la poesía y otros ensayos (traducción de Leonardo Williams). Madrid, Biblioteca Nacional y Extranjera, 1904. Un ejemplar con numerosas indicaciones de atenta lectura se guarda en los anaqueles de Moguer. Noticia de su publicación proporciona el trabajo de Ricardo Gullón, "Relaciones entre JRJ y los Martínez Sierra". Direcciones del modernismo. Madrid, Gredos, 1971; p. 249.

7. Deben consultarse H. Young, The Line in the Margin: Juan Ramón and his Readings in Blake, Shelley and Yeats. Madison, University of Wisconsin, 1980. Y Carmen Pérez Romero, Juan Ramón y la poesía anglosajona, Cáceres, Universidad de Extremadura, 1981.

8. El conocimiento la Estética hegeliana es indudable tanto en el caso de Unamuno como en el de Juan Ramón: "Leo poco - le escribe Unamuno a Clarín (10-V-1900)— porque leí mucho; sólo Hegel me ha alimentado para largo rato" (Marcelino Menéndez Pelayo/Miguel de Unamuno/Armando Palacio Valdés, Epistolario a Clarín ed. Adolfo Alas, Madrid, Escorial, 1941; p. 101). Sobre la incidencia de la estética hegeliana en Juan Ramón debe verse el fundamental rastreo -Schiller y Lessing al fondo- de Antonio Vilanova: "El ideal de la poesía desnuda en Juan Ramón Jiménez" en Juan Ramón Jiménez en su centenario (ed. Ricardo Senabre). Cáceres. Ministerio de Cultura, 1981; p. 275-306. Debo apostillar que el gran filósofo alemán define avant-la-lettre la poesía desnuda, al sentenciar: "El fin del arte es, precisamente, despojar tanto el fondo como la forma, de aquellos elementos ordinarios y prosaicos, depurando por la actividad creadora del espíritu el elemento racional de las cosas, su esencia, para representarlas en una imagen ideal y verdadera" (W.F. Hegel, De lo bello y sus formas (Estética) traducción de M. Granell, Madrid, Austral, 1980; p. 127). También la traducción de Hermenegildo Giner de los Ríos (Madrid, Daniel Jorro, 1908) de la versión francesa de Bénard de las Lecciones de Estética tiene numerosas anotaciones juanramonianas.

9. En un trabajo próximo abordaremos la filiación krausista de la estética juanramoniana a partir de los tiempos de Helios. 
Yo sólo Dios y padre y madre míos, me estoy haciendo, día y noche, nuevo y a mi gusto ${ }^{10}$.

No dejes ir un día sin cojerle un secreto, grande o breve.

Sea tu vida alerta descubrimiento cotidiano ${ }^{11}$.

Y en Piedra y cielo reitera:

¡Qué goce, corazón, este quitarte

día tras día, tu corteza, este encontrar tu verdadera forma, tierna, desnuda, palpitante, con ese encanto hondo, imán eterno, de las cosas motrices ${ }^{12}$.

El poeta se va haciendo a sí mismo, sin plan trazado, a través de un crear cotidiano: "Imposible toda norma. Salgamos de cada día y de nosotros cada día lo mejor que podamos. Y basta"13.

Ahora bien, tales reflexiones habían sido tempranamente formuladas por Unamuno. Decía el maestro salmantino que la vida traza el plan al vivirla $y$, en consecuencia, es inviable todo tipo de camino previo, y añadía:

No te empeñes en regular tu acción por tu pensamiento; deja que aquélla te forme, informe, deforme y transtorne éste. Vas saliendo de ti mismo, revelándote a ti propio; tu acabada personalidad está al fin y no al principio de tu vida [...] Tu vida es ante tu propia conciencia, la revelación continua, en el tiempo, de tu eternidad, el desarrollo de tu símbolo: vas descubriéndote conforme obras ${ }^{14}$.

Idea esta última, reiteradamente formulada por Juan Ramón Jiménez. Este obrar sucesivo supone descubrimiento gozoso de uno mismo, supone ser cada día y en cada instante eterno. "Vive al día, en las olas del tiempo, pero asentado sobre tu roca viva, dentro del mar de la eternidad; al día en la eternidad"15, aconsejaba Unamuno en 1900. Esta ambición encuentra una

10. JRJ, Eternidades (ed. V. García de la Concha). Madrid, Taurus, 1982; p. 105.

11. JRJ, Eternidades, ob. cit.; p. 106.

12. JRJ, Piedra y cielo (ed. M.E. Rincón). Madrid, Taurus, 1981; p. 92.

13. JRJ, Estética y ética estética, ob. cit.; p. 365.

14. Miguel de Unamuno, ¡Adentro!. Tres ensayos (1900). Obras Completas (ed. M. García Blanco). Madrid, Escelicer, 1966; t. I., p. 948.

15. Miguel de Unamuno, ;Adentro!, ob. cit;; p. 948. 
bellísima plasmación lírica en Juan Ramón, que escribe:

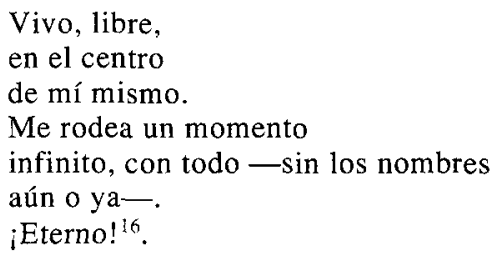

Ambición cuya formulación metodológica es el proceso de recreación - constante y de poesía en sucesión_- "La obra, como la vida, se resuelve sucesivamente" 17 . Proceso el de recreación, consustancial a la obra juanramoniana, en la que adquiere unas dimensiones insólitas en la poesía española, al que el poeta se sintió llevado por una necesidad íntima e inherente a su concepción poética. En este sentido quiero subrayar el interés de una carta de Unamuno a Juan Ramón (31-X-1915) en la que el maestro de Salamanca le decía: "Fuera de mis obligadas colaboraciones, hago poco [...] Apenas otra cosa que una Elegía de la guerra en verso, y retocar, pulir, podar y completar, poniendo y quitando, mi Cristo de Velázquez"18. En la terminología de Juan Ramón, Unamuno dedicaba su tiempo a una labor de recreación y depuración.

Atendiendo a lo expuesto anteriormente, la poesía desnuda sería el desvelamiento sucesivo de un yo sucesivo que vive al día la eternidad. De este desvelamiento forma parte también, como el propio poeta reconoce, una nueva visión del mundo que centra su interés en lo desnudo, en lo eterno subyacente a lo aparente, concreto o tangencial. Naturalmente la raíz de ambas postulaciones está en la identificación juanramoniana de la poesía con el alma, o mejor dicho, de la palabra pura y justa con la del alma, tras de la cual se encuentra el concepto romántico de la palabra poética ${ }^{19}$.

Si la poesía es alma (Juan Ramón lo afirma con sus bellísimas coordenadas habituales que suponen la identificación de la mujer desnuda con la poesía y con el alma del poeta:

16. JRJ, Eternidades, ob. cit.; p. 100.

17. JRJ, Estética y ética estética, ob. cit.; p. 342. También en Alerta y en un texto hasta hace poco inédito, Juan Ramón escribe: "El poeta es fatalmente sucesivo; y su papel, vigilar su creación emotiva súbita" (JRJ, Alerta ed. F.J. Blasco, Salamanca, Universidad de Salamanca, 1983; p. 155.

18. Cito por el estudio preliminar de Manuel García Blanco a Miguel de Unamuno, Obras Completas. Madrid, Afrodisio Aguado, 1958; t. XIII, p. 129. La carta vio la luz en la revista La Torre, 1 (1953); p. 171.

19. Aun sin detenerme quiero señalar la filaición romántica de esta concepción estética. Así Bécquer escribe en las Cartas literarias a una mujer (I): "La poesía es en el hombre una cualidad puramente del espíritu; reside en el alma, vive con la vida incorpórea de la idea y para revelarla necesita darle una forma". Cito por Gustavo A. Bécquer, Rimas (ed. J.C. Torre). Madrid, Castalia, Bécquer 1976; p. 229. 
Me andas por dentro

mujer desnuda

como mi alma ${ }^{20}$ ),

es también idea, es depuración formal de la idea:

Palabra justa y viva,

que la vida interior brota, lo mismo

que una rosa vaciada en un lucero;

[...]

final estrella del surtidor recto

de la fuente más honda

-la del alma-21.

Y no olvidemos que "depuración de la forma es únicamente depuración de la idea"22, según nos advierte el propio poeta saliendo al paso de cualquier interpretación que haga independiente la desnudez expresiva y formal de la experiencia primera como captación de la mismidad desnuda de la idea. Es más, la idea debe encarnarse en su verso como el alma que se sintiera a gusto en su cuerpo, y la obligación del poeta no es "vestir" esa idea, sino desnudarla, depurarla, quitarle la túnica coyuntural y pasajera para que la palabra sea la cosa misma - desnuda, esencial, eterna - creada por el alma del poeta en su trabajo gustoso y continuado.

Parece inaplazable en este punto recordar como raíz del quehacer juan"ramoniano, consolidado en Eternidades, el poema "Credo poético" que Unamuno antepuso a sus Poesías (1907). El gran maestro vasco sostiene como base del poema la identidad conflictiva entre el pensar y el sentir, aunque advirtiendo el esfuerzo intelectual por precisar el sentimiento:

Lo pensado es, no lo dudes, lo sentido.

¿Sentimiento puro? Quien ello crea,

de la fuente del sentir aún no ha llegado

a la viva y honda vena ${ }^{23}$.

Convicción según la cual el poeta es el pensador de verdaderos sentimientos, hijos de un alma desnuda, y que caló profundamente en Juan Ramón según se desprende de sus Ideas líricas (1908) en las que escribe: "Suele llamarse poeta sentimental a cualquier vano llorador de lugares comunes, y no es eso; el poeta sentimental es un pensador de verdaderos sentimientos. Los sentimientos son como las ideas una clara demostración" 24 .

20. JRJ, Piedra y cielo, ob. cit.; p. 94.

21. JRJ, Poesía (19I7-23) (ed. A. Sánchez Romeralo). Madrid, Taurus, 1981; p. 70.

22. JRJ, Estética y ética estética, ob. cit.; p. 267.

23. Miguel de Unamuno, "Credo poético". Poesías (ed. M. Alvar). Barcelona, Labor, 1975; p. 59.

24. JRJ, "Ideas líricas" (1908). Primeras prosas (ed. F. Garfias). Madrid, Aguilar, 1962; p. 448. 
Reflexión que nos advierte de la inclinación juanramoniana por desnudar su alma y dárnosla en sentimientos auténticos y personales a través de un nuevo lenguaje, en cuyo hallazgo debe ejercitarse el pensamiento, pues si "el sentimentalismo es el grado sumo del intelectualismo" 25 , un bellísimo poema de Estío exclama:

¡Con que segura frente se piensa lo sentido! ${ }^{26}$.

En Unamuno se abre desde esta perspectiva una dramática agónica del corazón y la cabeza. En Juan Ramón una inmensa estela en la que pensamiento y sentimiento darán forma a la poesía desnuda, cuya máxima exigencia será nombrar exactamente las cosas. No por ello dejará en el olvido esa dualidad leída en Unamuno. Así escribe en su "Diario poético" de los años republicanos: "Hay que sentir profundamente la idea, pensar con agudeza el sentimiento"27, que parece paráfrasis o recreación del verso inicial del "Credo" unamuniano, "Piensa el sentimiento, siente el pensamiento"28 y del capítulo inicial de Del sentimiento trágico de la vida, libro en el que Unamuno desarrollaría plenamente, dualidad encarnada en el hombre verdadero, el hombre de carne y hueso.

Debemos confirmar ahora que el ideal juanramoniano de la desnudez poética emparenta en varios puntos claves con el pensamiento de Unamuno. En primer lugar, la identificación de la poesía con la expresión del alma del poeta, de lo espiritual íntimo, es formulada en muchísimas ocasiones por Unamuno. Dos breves muestras: "El poeta es aquel a quien se le sale la carne de la costra, a quien le rezuma el alma"29, o poetizándolo:

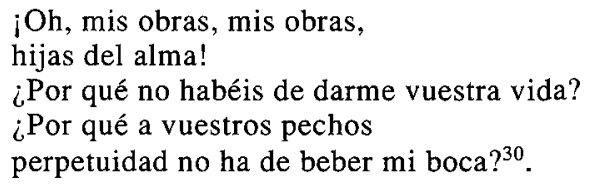

Versos cuya resonancia en numerorosos poemas juanramonianos de Piedra y cielo, Belleza y Poesía parece indudable.

En segundo lugar, el entender la tarea poética como el esfuerzo por

25. JRJ, Estética y ética estética, ob. cit.; p. 252.

26. JRJ, Estío (ed. G. Palau de Nemes). Madrid, Taurus, 1982; p. 70.

27. JRJ, Estética y ética estética, ob. cit.; p. 349.

28. Miguel de Unamuno, "Credo poético". Poesías, ob. cit.; p. 59.

29. Miguel de Unamuno, Soledad. La España Moderna (agosto, 1905); p. 5 y ss. Cito por Obras Completas, ob. cit.; t. I, p. 1256.

30. Miguel de Unamuno, "Para después de mi muerte". Poesías, ob. cit.; p. 66. 
captar con la mayor desnudez la esencia intrasferible y eterna de las cosas es equiparable a la tarea de depurar la idea, que constituye el meollo de la poesía desnuda, tiene una segura filiación unamuniana. Unamuno había señalado ya en 1895, en los importantísimos ensayos En torno al casticismo, la necesidad de mirar la idea desnuda; libre de toda costra rutinaria o castiza, "porque a una idea no hay que mirarla por de fuera, envuelta en el nombre para abrigarse y guardar la decencia; hay que mirarla por dentro, viva, caliente, con alma y personalidad"31. Reflexión que se extiende en múltiples matizaciones en sus ensayos y que alcanza formulación definitiva en sus Poesias, en las que afirma:

no te olvides de que nunca más hermosa que desnuda está la idea ${ }^{32}$.

Y, en efecto, la idea desnuda, la captación desnuda de la esencia de las cosas, es la urgencia juanramoniana de hacia 1916. No en balde el moguereño se decía a sí mismo:

No busques, alma, en el montón de ayer, más perlas en la escoria ${ }^{33}$,

y el ideal de desnudez se la aparecía no sólo como el más bello, sino como el único suyo y para siempre:

¡Oh pasión de mi vida, poesía desnuda, mía para siempre ${ }^{34}$.

En tercer lugar, el poeta moguereño se adentra en sí mismo en la busca de una mirada nueva y desnuda - la intuición poética es, en su mismidad, una intuición desnuda- con que recrear la esencia de las cosas:

31. Miguel de Unamuno, “La tradición eterna”. En torno al casticismo. Cito por Obras Completas, ob. cit.; t. I, p. 784.

32. Miguel de Unamuno, "Credo poético". Poesías, ob. cit.; p. 59.

33. JRJ, Eternidades, ob. cit.; p. 120.

34. JRJ, Eternidades, ob. cit.; p. 63. De modo tangencial quiero advertir que la identificación de "puro" y "desnudo" en este famoso poema conlleva una errónea lectura, injustificable desde la poética juanramoniana, en la que, por cierto, abundan las notas irónicas sobre la "poesía pura". Un botón de muestra no citado todo lo que se debiera: comenta Juan Ramón la publicación en la Revista de Occidente de seis sonetos y la elegía de Miguel Hernández, y escribe: "Todos los amigos de la poesía pura deben buscar y leer estos poemas vivos. Tienen su empaque quevedesco, su herencia castiza. Pero la áspera belleza tremenda de su corazón arraigado rompe el paquete y se desborda, como elemental naturaleza desnuda. esto es lo escepcional poético" (JRJ, "Con la inmensa minoría". El Sol (Madrid, 23-II-1936). Cito por M.G. Ifach (ed.), Miguel Hernández, Madrid, Taurus, 1975; p. 17. 
¿Que mi palabra sea

la cosa misma,

creada por mi alma nuevamente $!^{35}$.

Dicho de otro modo, y en reflexión del profesor García de la Concha: "El poeta ha de esforzarse por captar de manera desnuda la esencia poética de las cosas; ha de purificar sus ojos para intuir con la mirada sencilla de los primitivos o con esa forma de mirar del pueblo, que, en decantación de siglos, acierta a ver las cosas libres de las relaciones que la historia les va adicionando" "36. Tal planteamiento guarda una íntima relación con los conceptos de tradición eterna e intrahistoria establecidos por Unamuno en En torno al casticismo. R. Cardwell ha advertido que el Juan Ramón de 1900 se oponía a la utilización conservadora e inmovilista del término tradición y ha vinculado su verdadero uso con el concepto tal y como lo define Unamuno en $1895^{37}$, pero, en cambio, no se ha notado que lo eterno, lo esencial, es, en puridad, lo desnudo, aquello que se esconde tras la túnica de lo adquirido, de lo superficial, de lo falsamente castizo. Si se realiza esta notación se transparenta pronto el vínculo que une lo desnudo juanramoniano con la idea de intrahistoria fecundada por el primer Unamuno. Es decir, el problema de purificar la palabra, de depurarla de sus significados adquiridos es, en realidad, un problema de acercamiento a la intrahistoria, leído desde una óptica unamuniana. Resulta así que la búsqueda de la poesía desnuda es la búsqueda del fondo del ser del hombre mismo, de la tradición eterna:

Hay que ir a la tradición eterna, madre del ideal,que no es otra cosa que ella misma reflejada en el futuro. Y la tradición eterna es la tradición universal, cosmopolita ${ }^{38}$.

De este modo se comprende la segura deuda juanramoniana respecto de tan fructíferas ideas, y la correcta lectura de las mismas, sin contradicción con los continuados rechazos que Juan Ramón hizo a lo largo de su vida del casticismo alicorto y estéril: "declaro francamente que soy enemigo de ese eternismo casticista de mesón segoviano"39.

35. JRJ, Eternidades, ob. cit.; p. 61-2.

36. Víctor García de la Concha, "Prólogo" a JRJ: Eternidades, ob. cit.; p. 35.

37. Richard Cardwell, Juan Ramón Jiménez: The Modernist Apprenticeship (1895-1900). Berlín, Colloquium Verlag, 1977; p. 159 y ss.

38. Miguel de Unamuno, "La tradición eterna". En torno al casticismo. Obras Completas, ob. cit.; t. I, p. 797. Adviértase que una carta de Juan Ramón constata - la carta se puede fechar hacia 1915-: "Creo que la esencia de la poesía debe ser lo etemo, lo universal" (JRJ, Cartas Primera selección, ed. F. Garfias, Madrid, Aguilar, 1962; p. 223).

39. JRJ, "Recuerdo a José Ortega y Gasset". Clavileño, 24 (1953). Cito por La corriente infinita (Crítica y evocación) (ed. F. Garfias). Madrid, Aguilar, 1961. 
La forja de la poesía desnuda ha exigido un lentísimo camino de selección y depuración, en el que el poeta ha operado como un íntimo descubridor en busca de una palabra justa para la expresión de su propia alma. En este sentido lo singular ha sido el único univesal posible para el creador de Moguer — "Sólo es universal el alma del hombre" 40 _, recalando en la idea unamuniana de que lo singular no es particular sino universal, y de ahí el ¡adentro! sucesivo que hay que practicar, y que Unamuno vuelve a recordar —usando el mismo tono de 1900 - en un artículo de 1915 aparecido en Los Lunes de "El Imparcial". Bajo el rótulo de "¡Ensimísmate!, una vez más”, escribe, agudo y penetrante, el maestro vasco:

Y predicarse a sí mismo, predicar el desnudamiento y la expansión del propio yo es predicar y abogar por todos. Y además desnudar el propio yo es el mejor camino para desnudarnos de él, en cuanto esto es posible. Y desnudarse del yo individual, es llegar al otro yo tenebroso, al colectivo, al común, a esa tierra sobre que se levantan nuestros castillos todos. Porque las cercas, tapias y setos que los deslindan y amojonan no bajan sus cimientos hasta aquellos caminos soterraños que te decía. Cuando ensimismándote te adentras en ti mismo y avanzas, por tus tenebrosas íntimas galerías del alma, no sabes cuándo has salido de tu subsuelo espiritual para entrar en el de tu vecino. Bajo tierra como sobre el cielo, dentro de ti como fuera de todos, es todo común. Ensimísmate, pues, para enajenarte ${ }^{41}$.

Llegamos, por último, a una consideración de gran importancia. El poeta consigue la desnudez mediante el lenguaje poético y para ello Juan Ramón emplea una forma sencilla ${ }^{42}$, que no reclame la atención en sí misma, porque lo fundamental es - tarea de escultor y no de sastre-dar en su máxima pureza la experiencia primera, la intuición poética, auténtica y personal. El despego de las formas perfectas y suntuarias es fácilmente observable a partir del Diario: "La perfección de la forma artística no está en su exaltación, sino en su desaparición" ${ }^{\text {"43 }}$, escribe en una ocasión. Pues bien, también este radical intento de crear su propia expresión sucesiva que sea capaz de transmitir el pensamiento y el sentimiento poético que nacen del alma, tiene que ver, en su inicial concepción, con Unamuno. Juan Ramón

40. JRJ, Estética y ética estética, ob. cit.; p. 249.

41. Miguel de Unamuno, “Ensimísmate!”. Obras Completas. Madrid, Afrodisio Aguado, 1958; t. IX, p. 842 .

42. Con razón ha podido escribir el profesor Manuel Alvar en un penetrante estudio: "Nadie como él, amante de lo sencillo y espontáneo, pero nadie como él hostil a lo que no sea el fruto elaborado con pasión y trabajo" ("Juan Ramón Jiménez y la palabra poética". Actas del Congreso Internacional de Juan Ramón Jiménez ed. J. Urrutia, Huelva, Instituto de Estudios Onubenses, 1983; t. I., p. 20).

43. JRJ, Estética y ética estética, ob. cit.; p. 249. 
aprendió en sus ideas, divulgadas en soberbios ensayos (pienso en Intelectualidad y espiritualidad, El secreto de la vida o Soledad), que la transparencia, la libertad, el verso como el agua, es la máxima aspiración formal del poeta, que debe empeñarse en desvestir el lenguaje de su dimensión histórica, social, racional, para poder presentar el lenguaje del alma, el desnudo, el de pensamiento y sentimiento exactos, que no es otro que el de la poesía desnuda. Y no podía ser de otro modo: a una idea desnuda la debe acompañar un cuerpo desnudo, a los hijos de un alma que se desviste rítmicamente no se les puede ornamentar innecesariamente después.

Lo propio, lo válido, lo esencial, proviene para Unamuno de la savia del alma:

Para expresar un sentimiento o un pensamiento que nos brota desde las raíces del alma, tenemos que expresarlo con el lenguaje del mundo, de la sociedad que nos rodea, los elementos que dan consistencia, cuerpo y verdura a ese follaje, lo mismo que la planta que toma del aire los elementos con que reviste su follaje. Pero la fuente interna, la sustancia íntima e invisible, le viene de las raíces.

El lenguaje de que me sirvo para vestir mis sentimientos y mis ideas es el lenguaje de la sociedad en que vivo, es el lenguaje de aquellos a quienes me dirijo; las imágenes las mismas, los conceptos en que vierto su savia, son las imágenes y los conceptos de los que me oyen; pero la savia, esa savia vivificante que desde las raíces sube a mis frutos, esa savia que no se ve, ésa es mía. Y es la que da a mis frutos, la que da a los frutos de todo hombre, el sabor que tengan. Hay frutos desabridos que a nada saben, que no dejan dejo de lo que repiten, que parecen sosos productos de estufa; y es que esos frutos no provienen de semilla, sino de gajo, de injerto tal $\mathrm{vez}^{44}$.

Juan Ramón también afirma esta dimensión y postula la belleza de una obra que contenga la idea desnuda en un verso desnudo, en un "éstasis que no mate lo vivo" 45 , porque "no hay forma mejor ni peor, sino ideas y sentimiento exactos o imperfectos" ${ }^{46}$, y porque el "número, acento, rima, nunca están en el verso, sino siempre en el poeta" ${ }^{4}$, que además dice saber que "Nada termina en forma sino en idea" ${ }^{48}$. Idea que sirve para que el poeta construya su yo sucesivo, prestando en armoniosa y amorosa reciprocidad su conciencia al universo:

44. Miguel de Unamuno, "El secreto de la vida". La España Moderna, (julio, 1906). Obras Completas, ob. cit., t. III., p. 879.

45. JRJ, Cuadernos (ed. F. Garfias). Madrid, Taurus, 1971; p. 225.

46. JRJ, Cuadernos, ob. cit.; p. 235.

47. JRJ, Cuadernos, ob. cit.; p. 223.

48. JRJ, “Aforismos inéditos". Nueva Estafeta, 12 (1979); p. 4. 
De pronto, me dilata

mi idea,

y me hace mayor que el universo.

Entonces, todo

se me queda dentro. Estrellas

duras, hondos mares,

ideas de otros, tierras

vírgenes, son mi alma ${ }^{49}$.

La poesía desnuda, perpetua y luminosamente haciéndose, se vertía en verso desnudo, libre, blanco -así lo llama en diversas ocasiones Juan Ramón- dado que ése era el cauce para un agua inagotable, esencial y eterna. Años después de esta "conversión unamuniana", el poeta de Moguer no tenía reparos en vincular su verso desnudo al maestro salmantino: "El verso libre de Unamuno es en gran parte orijen del mío y luego de todos los que escribieron y escriben en verso libre en España y en Hispanoamérica" ${ }^{\text {"50. }}$.

A la luz de estos breves y complementarios asedios creo que el aprendizaje juanramoniano del pensamiento del primer Unamuno resulta indudable. En efecto, si el gran poeta de Moguer se empeñó en la poda de la maleza modernista para conquistar la desnudez poética, entre múltiples estímulos, uno, seguro y señero, fue el riquísimo filón de ideas que atesoraban los ensayos de Miguel de Unamuno, cuyas lecciones progresivamente asimiló la juventud modernista y noventayochista.

49. JRJ, Piedra y cielo, ob. cit.; p. 144-5. Algo se dice de la deuda unamuniana en este punto concreto en el excelente estudio de M. Coke-Enguídanos: Word and Work in the Poetry of Juan Ramón Jiménez. London, Tamesis Books, 1982.

50. JRJ, Alerta, ob. cit.; p. 65 . 